\title{
ANÁLISE DE PROGRAMAS DE EDUCAÇÃO AMBIENTAL DO SETOR PÚBLICO DE OURO PRETO (MG)
}

\author{
Simone Fernandes Machado ${ }^{1}$ \\ Ricardo Eustáquio Fonseca Filho² \\ Frederico Martino Simonini da Silva ${ }^{3}$
}

Resumo: O presente estudo analisa os programas de Educação Ambiental (EA) promovidos pelo setor público em Ouro Preto/MG e propõe uma metodologia para o diagnóstico, com o intuito de averiguar a sua eficiência e continuidade. A metodologia considerou: revisão bibliográfica e documental; sistematização analítica com métodos de Educação Ambiental dos programas de EA da Prefeitura Municipal de Ouro Preto de 2005 a 2015 envolvendo a comunidade residente e os visitantes das unidades de conservação municipais. Os resultados encontrados possibilitaram o apontamento de ações para redução de custos desnecessários, melhorias no foco, na singularidade, na continuidade de cada programa como programa de Estado e não de Governos.

Palavras-chave: Meio Ambiente; Oceanos Azuis; Unidades de Conservação.

\footnotetext{
1 Universidade Federal de Ouro Preto. E-mail: sissamachadofernan@hotmail.com.

2 Universidade Federal de Ouro Preto: E-mail: ricardo.fonseca@ufop.edu.br.

${ }^{3}$ Fundação Euclides da Cunha: E-mail: frederico.martino@gmail.com.
}

revista brasileira educação ambiental 


\section{Introdução}

A Constituição Federal de 1988, em seu Art. 225, dispõe que "o meio ambiente é um bem de uso comum do povo e um direito de todos os cidadãos, das gerações presentes e futuras" (BRASIL, 1988), cabendo, portanto ao Poder Público e a coletividade a obrigação de preservá-lo e defendê-lo. Nesse contexto, cabe ao Setor Público instituir e gerir programas de Educação Ambiental (EA) para orientar o comportamento da comunidade para ações menos predatórias para com o meio ambiente. Ressalta-se que a posse e domínio das Unidades de Conservação, prioritárias para preservação, são atribuídas ao Setor Público, exceto a Reserva Particular do Patrimônio Natural, privada. Estas, previstas pela Lei no 9.985 (BRASIL, 2000) que institui o Sistema Nacional de Unidades de Conservação da Natureza - SNUC (BRASIL, 2000).

Como consequência do regime de gestão realizada pelo setor público, destacam-se três características que se tornam problemáticas na obtenção de êxito dos programas de EA: à descontinuidade administrativa, o imediatismo e a fragmentação das ações. Estudos de UC de Minas Gerais demonstraram parte destas questões (LIMA et al., 2005; REZENDE et al., 2010). Sobre esta observação, esclarece-se que os gestores públicos anseiam por resultados em curto prazo, preferencialmente dentro do período de quatro anos que compreende o mandato eleitoral, ao passo que o retorno positivo das atividades preservacionistas geralmente manifesta-se em longo prazo e são de difícil mensuração Tais características, aliadas às mudanças frequentes ocorridas nos quadros de chefias e, por consequência, na visão dos valores dos programas de EA, tornam-se empecilhos para a obtenção de bons resultados e, por vezes, resultam no desperdício de recursos físicos, financeiros e humanos aplicados em tais programas.

Um desses programas, intitulado "A Escola Vai ao Parque", inclui a visitação aos Parques Naturais Municipais de Ouro Preto, dentre estes, está o Parque Natural Municipal das Andorinhas-PNMA, criado pela Lei municipal ํㅡ. 390 de 1968 com objetivo de preservar os recursos naturais da região de Ouro Preto e a nascente do Rio das Velhas (OURO PRETO, 1968), é uma UC municipal pertencente à categoria de Proteção Integral. Em 2005 a Lei Municipal no. 69/2005 alterou a sua área inicial de $1 \mathrm{~km}$ ao entorno do principal atrativo, a Cachoeira das Andorinhas (Figura 1), para 557 hectares a fim de ampliar a área a ser preservada (OURO PRETO, 2005). A visitação aos atrativos naturais desta UC acontece durante todo o ano, com aumento em períodos específicos, como o verão e as férias escolares (Figura 2) (MACHADO, 2013, p.13). 


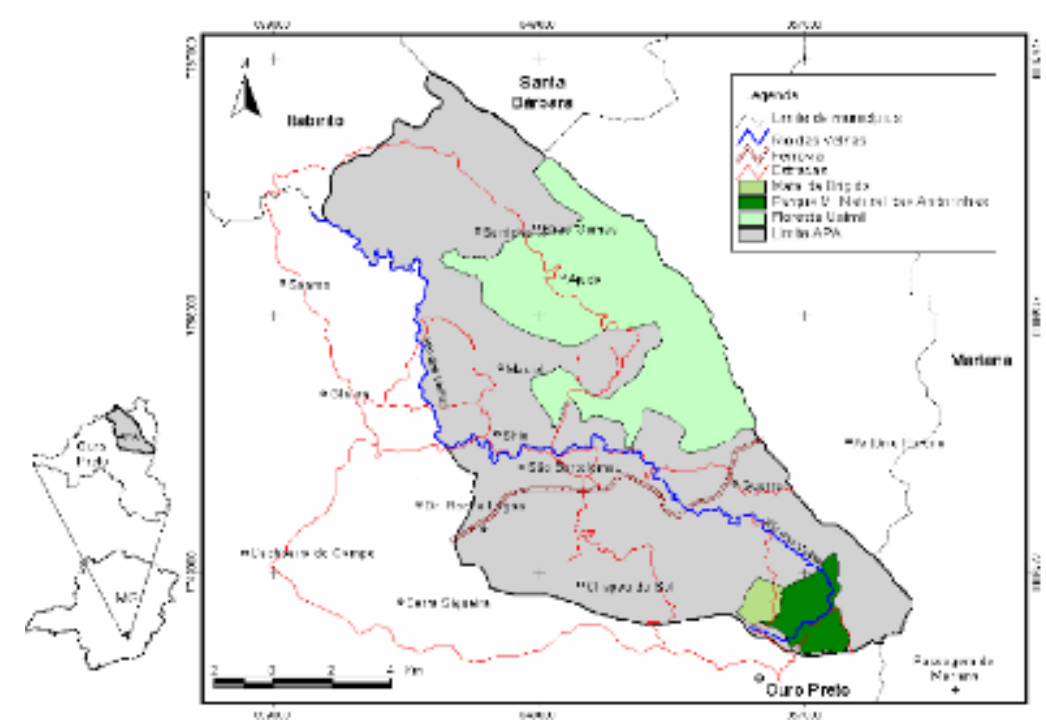

Figura 1: Localização e acesso ao Parque Natural Municipal das Andorinhas, Ouro Preto /MG. Fonte: Silvia Magalhães (sd).

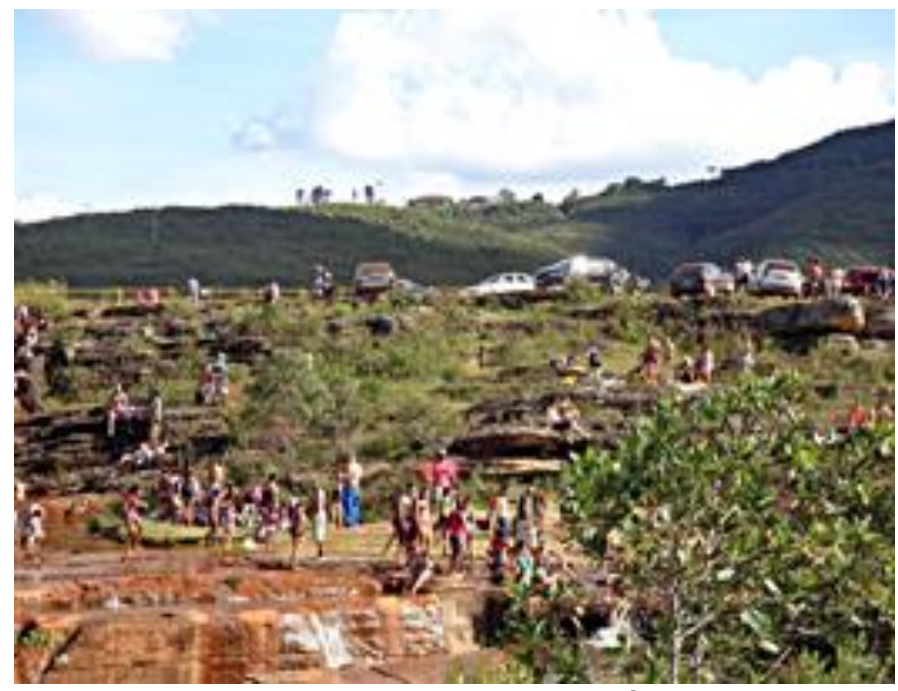

Figura 2: Cachoeira das Andorinhas, principal atrativo turístico do Parque homônimo e parte das nascentes altas do Rio das Velhas, Ouro Preto/MG com turismo de massa em fim de semana. Fonte: Simone Machado (2013).

Considerando que o desenvolvimento desordenado das atividades de visitação e recreação em UC pode comprometer os demais objetivos fundamentais de preservação para os quais elas foram estabelecidas, os programas de EA são desenvolvidos como uma forma de orientar o comportamento dos visitantes, bem como das comunidades residentes para ações menos predatórias para com o meio ambiente.

Sobre a necessidade de orientar a população para ações menos predatórias, Gatti (2013) ressalta que conhecimento é um determinante de desigualdade social. Nesse contexto, quando voltados para a comunidade, os programas de EA ampliam o ensino de práticas sustentáveis para além do espaço escolar, aproveitando-se do seu caráter transdisciplinar e torna-se 
ferramenta importante para educar a população local para as responsabilidades e benefícios que envolvem a preservação de uma UC, diminuindo antagonismos culturais existentes entre os visitantes de UC e à comunidade residente. De acordo com Matheus et al. (2005) a comunidade necessita de ações que desenvolvam o senso comunitário para se sentirem parte de um todo e conscientes do seu poder de mudança, engajando-se na melhoria da qualidade de vida.

A importância da visitação em áreas de preservação na construção de uma consciência ambiental é corroborada pela afirmação de Cunha (2016) que ressalta que espaços educativos envolvem seres humanos em convivência, não há como desconsiderar os processos formativos que dela derivam e as formas de ver o mundo. Gatti (2013) acrescenta que as práticas educacionais são processos da maior importância e têm seus fundamentos teóricos, tais práticas associam-se a uma filosofia educacional. Para a autora, práticas geram teorização e teorização geram práticas. Logo, práticas são fatos culturais e assim precisam ser significadas. A autora defende ainda que, conforme concepção de ciência positivada, segundo a concepção cientifica do mundo positivista, o conhecimento acerca do mundo é produzido através das ciências empíricas e não apenas baseado na razão/método.

Essa interação entre a comunidade e os objetos de estudo, pela qual há incentivo para a curiosidade e a troca de conhecimentos, apresenta-se como uma poderosa ferramenta educacional, visto que está ancorada na Ecologia dos Saberes proposto por Santos (2010), que visa recuperar práticas e saberes de grupos sociais diversos que, em função do capitalismo e dos processos coloniais, ao longo do tempo foram sendo colocados, social e historicamente, em uma postura de meros objetos ou ainda de matéria-prima dos saberes que dominavam (Epistemologia do Norte) e foram considerados por muitos séculos como a única verdade ou os únicos saberes válidos.

Entretanto, entre os problemas enfrentados para o estabelecimento de atividades de Educação Ambiental em Ouro Preto, consta a visão dos seus gestores voltada para obtenção de resultados em curto prazo, ao passo que o retorno positivo das atividades preservacionistas geralmente se manifesta em um longo prazo, o que acarreta em ações descontínuas (LAYRARGUES, 2002; JACOBI, 2003). Outro problema é a dificuldade de mensurar os resultados correlacionados tendo em vista o seu caráter intangível (HENRIQUES et al., 2007).

Com base no exposto, o presente estudo propõe um modelo para realização de análise dos programas de EA existentes em Ouro Preto, promovidos pela Secretaria Municipal de Meio Ambiente, com vistas à elaboração de um plano estratégico para minimizar os impactos do regime imediatista que usualmente caracteriza o setor público. Para testar a viabilidade de tal modelo, foi realizado o diagnóstico dos programas de EA desenvolvidos pelo setor público, em Ouro Preto - Minas Gerais (MG), no período compreendido entre os anos de 2005 e 2015. 


\section{Materiais e Métodos}

Os materiais e métodos utilizados abrangeram quatro etapas: I. Revisão bibliográfica; II. Levantamento e análise documental; III. Sistematização analítica dos programas de EA com base em metodologias de Educação Ambiental e patrimonial; IV. Apontamentos para melhorias utilizando 0 modelo de planejamento estratégico.

$\mathrm{Na}$ revisão bibliográfica pesquisaram-se modelos de avaliação aplicáveis ao objeto de estudo. Já na documental inventariaram-se programas de EA da Secretaria Municipal de Meio Ambiente de Ouro Preto - SEMMA escolhendo-se os mais ativos no período de 2005 a 2015, sendo estes: 1. Flores nas Pedras Camarinhas; 2. Plano Integrado de Prevenção e Combate a Incêndios Florestais; 3. Curso de Educação Ambiental; 4. A Escola Vai ao Parque; e 5. Uma vida, uma árvore.

Em seguida os programas foram organizados em um quadro analítico, subdivididos em dez variáveis de análise para aplicação das metodologias de Educação Ambiental (MATHEUS et al., 2005) e patrimonial (HORTA, 1999) propostas. A valoração considerou a nota 1 (um) para atividade presente no projeto e 0 (zero) para inexistente.

Por fim, para viabilizar a execução da análise e proposição de sugestões para melhorias dos programas de EA, foi aplicada a metodologia "Curva de Valor" (KIM; MAUBORGNE, 2005) na qual foram elencadas três características essenciais para uma boa estratégia, sendo estas: 1. Foco, voltado para o perfil estratégico; 2. Singularidade, enfatizando no diferencial e fugindo da tendência de acompanhar o perfil de atributos presentes outros programas; e 3 . Elaboração de mensagem consistente, favorecida pela identificação de atributos exclusivos, enaltecendo a diferenciação.

\section{Principais programas de Educação Ambiental da Prefeitura Municipal de Ouro Preto no Parque Natural Municipal das Andorinhas de 2005 a 2010}

Foram identificados cinco programas de Educação Ambiental promovidos pela Secretaria de Meio ambiente entre os anos de 2005 e 2015:

\section{Projeto 1 - Flores Nas Pedras Camarinhas}

A Associação dos Extratores de Quartzito das Camarinhas realizava extração irregular da rocha quartzito na área denominada "Camarinhas" (Figuras 3 e 4), localizada nas coordenadas $20^{\circ} 22^{\prime}$ 'W e $43^{\circ} 30^{\prime} \mathrm{S}$, nos limites do PNMA e APAECA, às margens de uma das principais nascentes do Rio das Velhas, contribuinte do Rio São Francisco. Composta pela comunidade residente nos bairros do entorno da UC, a extração mineral era responsável por uma das práticas mais predatórias na área, pois promovia o desmatamento de espécimes, nativas e endêmicas, bem como contaminava os cursos hídricos e suprimia parte das nascentes d'água da UC. 


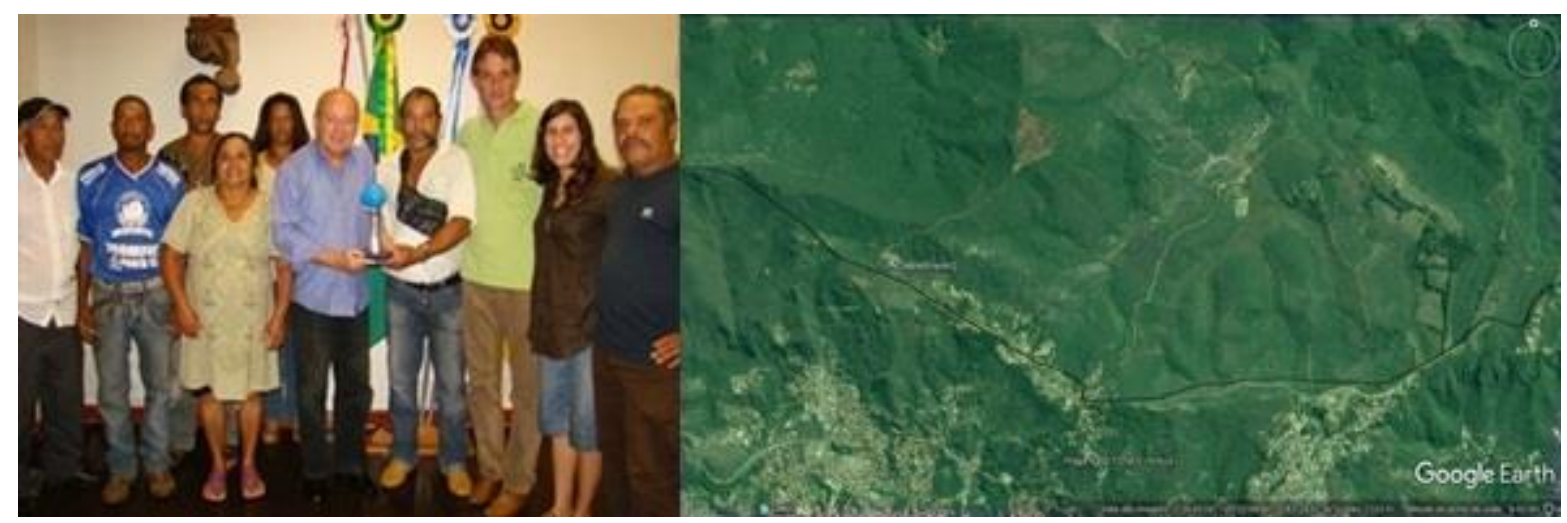

Figura 3: Premiação Projeto Flores e

Figura 4: Imagem de satélite com localização (círculo Nascentes do Velhas".

Fonte: O Inconfidente (2016). branco) da antiga pedreira de quartzito das Camarinhas, na Área de Proteção Ambiental Estadual Cachoeira das Andorinhas (linha preta) e entorno do Parque Natural Municipal das Andorinhas, Ouro Preto (MG).

Fonte: modificado de Google Earth (2017).

Diante deste passivo ambiental, o "Projeto Flores nas Pedras Camarinhas" se constituiu na substituição da atividade de extração mineral pela produção de mudas de plantas ornamentais nativas. Para tanto, a SEMMA promoveu encontros com os associados com vistas a assegurar decisões participativas - como propôs Gastal e Moesch (2007, p.48) - para que estes indicassem caminhos para o planejamento adequado baseando-se no seu saber empírico da realidade encontrada, e firmou parcerias com o Instituto Mineiro de Gestão das Águas - IGAM e Fundo de Recuperação, Proteção e Desenvolvimento Sustentável das Bacias Hidrográficas do Estado de Minas Gerais - Fhidro.

Para auxiliar os associados no novo projeto, a Secretaria forneceu apoio técnico e administrativo para regularizar a associação e promover o desenvolvimento das atividades de produção de mudas por meio de palestras de empreendedorismo e saúde, além de Educação Ambiental. Depois de formalizada a associação, a Prefeitura Municipal de Ouro Preto - PMOP cedeu um espaço onde construiu um viveiro com os insumos necessários para o início das atividades de jardinagem. Tais etapas foram realizadas em quatro anos, de 2009 a 2012.

Os estudos prévios para a execução do projeto apontaram para a existência de um contexto social similar à crise nos modelos de formação mencionada por Cunha (2016), havia insatisfação e reivindicação dos grupos sociais por equidade, reconhecimento social e dignidade humana. A autora menciona que para uma escola justa, que faz justiça social, é preciso mestres preparados e compromissados. Escola justa é aquela que inclui e lida com heterogeneidades, respeita e leva a aprendizagens eficazes. Logo, o papel fundamental, levar a comunidade a aprender / compreender conhecimentos já produzidos, ao mesmo tempo, formando-os em valores para a vida humana. $\mathrm{Na}$ circunstância, práticas educacionais tornam-se processos da maior importância 
desde que tenham seus fundamentos teóricos e associam-se a uma filosofia educacional.

Em 2013 houve troca da gestão pública municipal e a equipe responsável pela pasta ambiental infelizmente não deu prosseguimento aos trabalhos. No entanto, apesar dos percalços encontrados para o desenvolvimento da nova atividade de jardinagem e recuperação de áreas degradadas, observa-se que tal iniciativa educacional resultou em melhorias na qualidade ambiental da área afetada pela antiga extração mineral na UC que atualmente encontra-se com mata nativa na fase intermediaria de sucessão ecológica, com a intervenção da atividade minerária e nas comunidades do entorno que se tornaram mais conscientes quanto à necessidade de preservação da área e não mais retornaram as atividades minerarias predatórias no local. O que corroborou com a teoria apresentada "práticas geram teorização e teorização geram práticas". Praticas são fatos culturais e assim precisam ser significadas.

\section{Projeto 2 - Plano Integrado de Prevenção e Combate a Incêndios Florestais}

Devido aos altos índices de incêndio na região de campo rupestre de altitude na qual parte do PNMA se insere, o Plano Integrado de Combate a Incêndios foi elaborado visando ações de prevenção e combate a incêndios florestais. Dentre as suas atividades constam: elaboração de campanhas educativas nas escolas e com a comunidade (Figura 4); formação da brigada voluntária - Brigada Ouro Preto; e integração das ações das instituições locais que atual em projetos similares como Corpo de Bombeiros Militar de Minas Gerais - CBMMG, Polícia Militar Ambiental de Minas Gerais, Instituto Estadual de Florestas - IEF e Guarda Municipal de Ouro Preto (Figura 5). Para sediar das atividades do projeto, foi disponibilizada uma sala do Centro de Visitantes do PNMA.

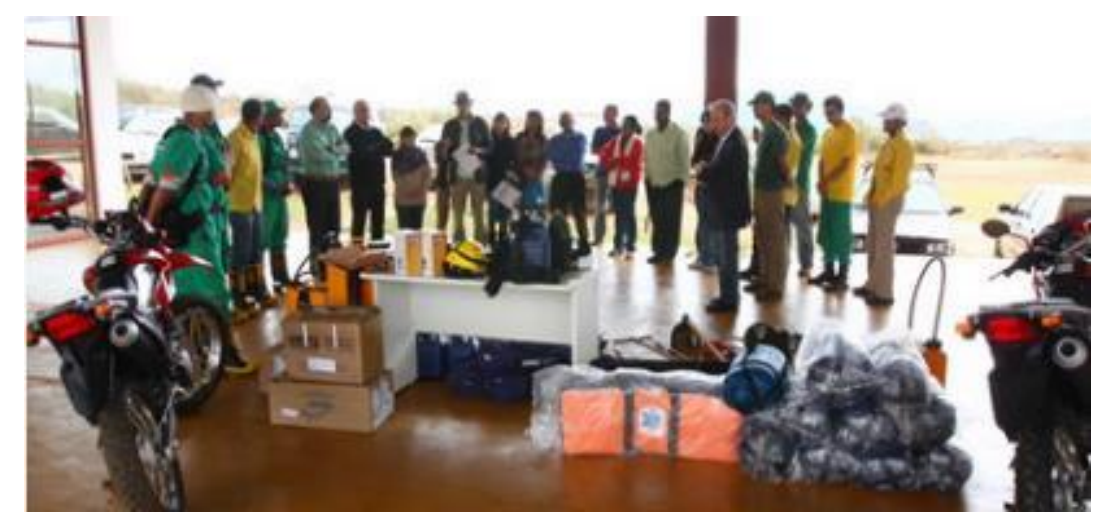

Figura 5: Treinamento da Brigada de Incêndio no Parque Natural Municipal das Andorinhas, Ouro Preto (MG). Fonte: Neno Vianna (2011). 


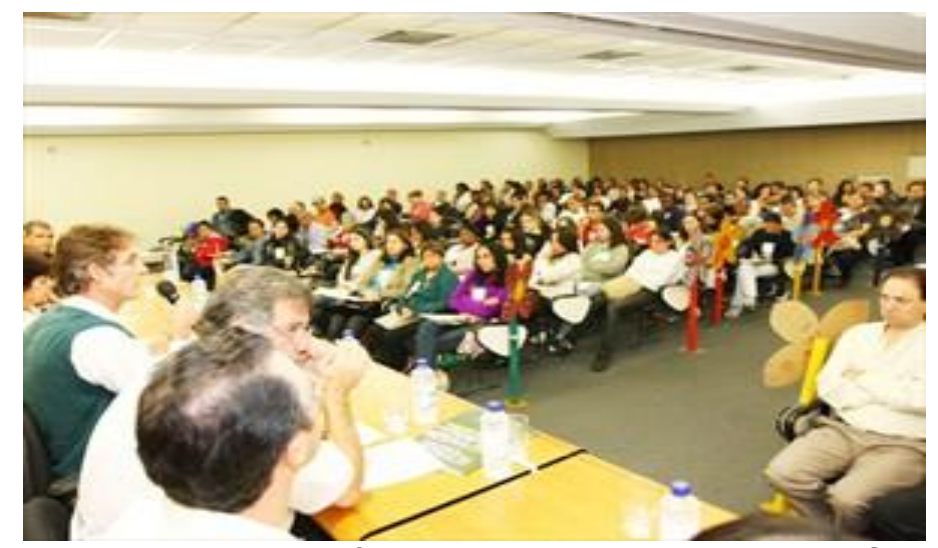

Figura 6: Mesa durante IV Fórum de Educação Ambiental de Ouro Preto.

Fonte: O Inconfidente (2010).

Os principais problemas enfrentados para manter o projeto são a falta de insumos, devido ao excesso de burocracia para adquiri-los por intermédio de órgãos públicos, criando a dependência de doações de empresas privadas - em especial minerárias como Vale e Samarco - e da comunidade; falta de logística no combate a incêndios; carência de planejamento nas atividades educacionais previstas, que são realizadas de forma esporádica e descontínua; características geológico-geomorfológicas que dificultam o acesso em determinados locais para promover o combate ao fogo.

Sobre a eficiência do programa, o cruzamento de dados obtidos pelo Instituto Nacional de Meteorologia, Instituto de Pesquisas Espaciais, Organização Não-Governamental Brigada 1 e CBMMG apontam para um quadro de redução de incêndios criminosos na UC e no entorno em períodos de seca em geral nos meses de maio a agosto nos climas tropicais de altitude - que foram antecedidos por atividades de Educação Ambiental de prevenção a incêndios promovidos pelo projeto. Quanto ao status do projeto, este está atualmente ativo e em execução.

Tal projeto enquadra-se nas premissas de gestão participativa propostas por Cunha (2016) já que quem ministra o treinamento conduz o processo, mas, partilha com os estudantes sobre o processo. Há uma reconfiguração dos saberes: reorganização da relação teoria/prática, que nasce da leitura da realidade, portanto, a prática social é condição para problematização do conhecimento que os estudantes precisam produzir no curso. A mediação exercida pelos palestrantes é responsável pela inclusão de relações sócio afetivas como condição de aprendizagem. Inclui a capacidade de lidar com as subjetividades dos envolvidos, articulando essa dimensão com o conhecimento tornando-os protagonistas nas relações de preservação que reconhecem que tanto os alunos como os professores representantes do setor público são sujeitos da prática pedagógica e, mesmo em posições diferentes, atuam como sujeitos ativos de suas aprendizagens. 


\section{Projeto 3 - Curso de Educação Ambiental}

O Curso de Educação Ambiental iniciou-se em 2006, com objetivo de promover a compreensão a respeito dos recursos naturais, sua relação e interação com o ser humano, por meio de exposição e discussão de temas relacionados com o meio ambiente a nível global, regional e local com uma abordagem ampla sobre a EA, seus conceitos, finalidades e problemáticas.

O projeto envolveu a rede pública e particular de ensino de Ouro Preto, lideranças comunitárias, funcionários do setor produtivo, Secretaria Municipal de Educação - SEEDU, Projeto Manuelzão, Agência de Desenvolvimento de Ouro Preto, a empresa Novelis, bem como O Instituto Federal de Minas Gerais - IFMG e a Universidade Federal de Ouro Preto - UFOP.

As três turmas, formadas nos anos de 2006, 2007 e 2008, contribuíram para capacitar multiplicadores de práticas sustentáveis direta e indiretamente em UC, como o PNMA. Ressalta-se que, conforme Ruschmann (1997), não só visitantes precisam ser educados para proteger a natureza, as ações de educação devem, indispensavelmente voltar-se ao poder público, uma vez que cabe a este diretamente a função de gerenciar os recursos naturais. Quanto ao status do projeto, este se encontra paralisado desde 2010, sem previsão para reativação.

A relevância do projeto encontra-se ancorada nas premissas das inovações (CUNHA, 2016) que se materializam pelo conhecimento de formas alternativas de saberes e experiências. Ressalta-se que situação atual exige uma reconfiguração dos papeis atribuídos aos professores e alunos, numa relação mais horizontal, com responsabilidades e autorias partilhadas.

\section{Projeto 4 - A Escola vai ao Parque}

A Escola vai ao Parque trata-se de um projeto implantado em 2008 pela SEMMA em parceria com a Secretaria Municipal de Educação de Ouro Preto (Figura 6). O projeto tem por premissa desenvolver e trabalhar temáticas preservacionistas e o desenvolvimento de uma visão crítica dos alunos frente às problemáticas ambientais, com base no contexto local e conhecimento empírico dos alunos. As atividades do projeto contam com palestras educativas, atividades de criação e apropriação como desenhos, confecção de textos, poesias entre outros. 


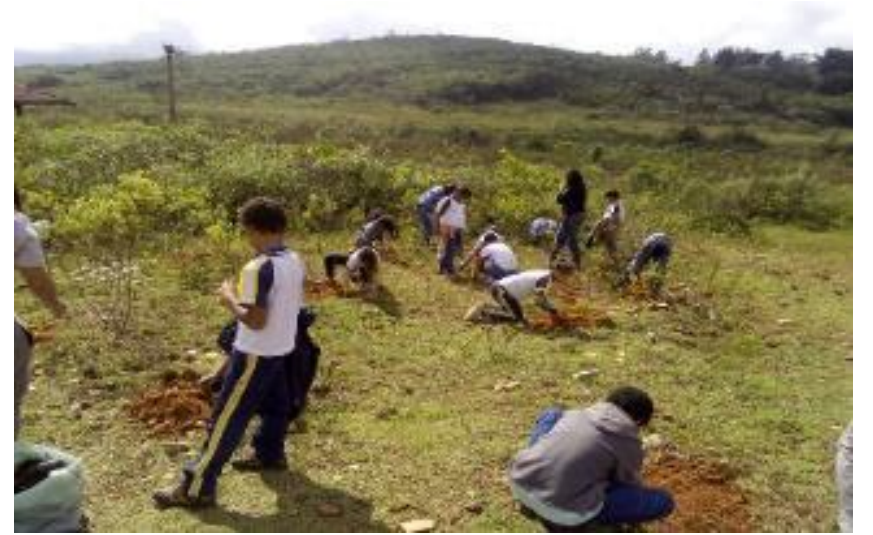

Figura 6: Estudantes da 5ª série da Escola Municipal Isaura Mendes visitam o PNMA, Ouro Preto/MG. Fonte: O Liberal (2016a);

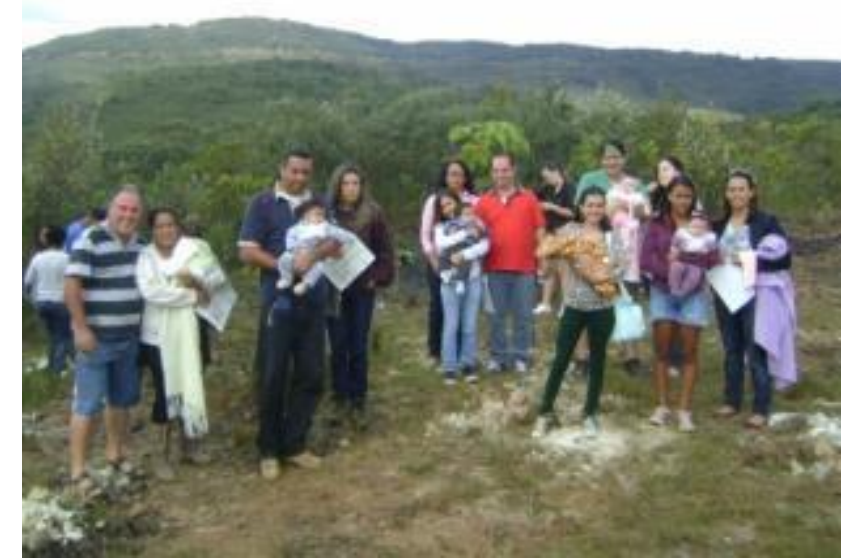

Figura 7: Foto com pais e árvores plantadas em Ouro Preto (MG) pelo Projeto Uma Vida, Uma Árvore. Fonte: PMOP (2013).

A metodologia do projeto divide-se em três etapas: Na primeira etapa, os alunos estudam as temáticas previamente estabelecidas em sala de aula. $\mathrm{Na}$ segunda etapa, estes são levados para uma aula em campo em uma unidade de conservação municipal, geralmente ao PNMA na qual são incentivados a conhecer os principais atrativos do local, bem como observar as nascentes, vegetação, fauna, solo, clima entre outros e relacioná-los as temáticas estudadas em sala de aula. Após a visita ao Parque, os alunos realizam a terceira etapa, relacionada à criação e apropriação, nela os alunos desenvolvem atividades de pintura, escultura, produção de texto, teatro e outras orientadas pelos professores onde buscam apropriar-se do observado na aula de campo ao próprio cotidiano.

As Práticas educacionais adotadas por este projeto remetem ao proposto por Gatti (2013) com base na concepção de ciência positivada, segundo a qual a concepção cientifica do mundo positivista, produzimos conhecimento acerca do mundo através das ciências empíricas e não apenas baseado na razão/método. Logo, as práticas educativas significativas deste projeto se ancoram em: domínio de conhecimento, sensibilidade cognitiva, compreensão das situações de aprendizagem, relacionamentos didáticos, Revbea, São Paulo, V. 14, No 3: 09-30, 2019. 
fazendo emergir atitudes éticas. Entretanto, pratica social com significado e não pode ser tomada como simples receita, ou confundida com tecnicismos moderados.

Para Gatti (idem) a educação está imersa na cultura e não se encontra apenas vinculadas às ciências; $O$ papel do professor é central; o núcleo do processo educativo é a formação do aluno. O Manifesto dos Pioneiros da educação nova vislumbrava a possibilidade de interferir na organização da sociedade brasileira do ponto de vista da educação. Talvez seja este o objetivo principal deste projeto, incentivar atitudes sustentáveis e éticas voltadas com base curricular voltada para a educação de crianças.

Estima-se que de 2008 a 2012, o projeto atendeu anualmente 35 escolas municipais e cerca de 2.500 alunos. Após 2012, o projeto teve redução gradativa no quantitativo sendo praticamente extinto em 2014 por razão de redução de efetivo e trocas constante de gestores que afetaram a etapa de planejamento e gestão deste. Em 2015, houve tentativa de recuperação de suas atividades, entretanto, sem êxito. Atualmente o projeto encontra-se parcialmente inativo, entretanto há uma proposta de revitalização deste para o ano de 2017, contando com parceria de uma empresa municipal Fundação Gorceix.

\section{Projeto 5 - Uma vida, uma árvore}

O Projeto uma vida, uma árvore trata-se de uma iniciativa da Rede Globo Minas que contou com a parceria da SEMMA e da Santa Casa de Misericórdia de Ouro Preto com o objetivo de recuperar áreas degradadas e de melhoria de qualidade de vida da população local. Neste, para cada criança nascida no município de Ouro Preto, uma árvore foi plantada em um dos parques municipais, em evento realizado mensalmente (Figura 8).

A árvore, nativa da região, é fornecida pela SEMMA oriunda do Viveiro Municipal e plantada pelos pais, com acompanhamento de um técnico agrícola da secretaria, num evento previamente agendado. Para desenvolver vínculo entre os pais, a criança e a causa preservacionista, a árvore ganha uma etiqueta com o nome da espécie e o da criança recém-nascida e os pais ganham um cartão do projeto contendo os mesmos dados. Entretanto, apesar de promover a recuperação de áreas desmatadas, a prática do plantio de árvores não é algo inovador e não incentiva a reflexão.

Similarmente estima-se que durante o período em que o projeto "Uma vida, uma árvore" esteve ativo, cerca de 1.500 árvores foram plantadas nas nascentes do Parque Natural Municipal das Andorinhas.

Alves (2012) faz uma crítica a este tipo de modelo educativo utilizado no projeto. Tal crítica consiste no fato de que o conhecimento histórico ajuda a desconfiar da eficácia do modelo de educação que reduz a formação à titulação, na pressa de se produzirem índices animadores, no caso do projeto, a obtenção de um certificado às pressas. A autora chama a atenção para as armadilhas metodológicas, para esta, Nada é tão simples como parece, quando se leva em 
consideração essas temporalidades. Logo, é um risco desconsiderar o diálogo com a história, seja ao se fazerem presentes todas as questões, seja reduzindo o passado a uma narrativa simples e ingênua.

\section{Resultados e Discussão}

\section{Educação Ambiental e patrimonial em Ouro Preto/MG}

Aplicando a metodologia de avaliação de programas de EA foi possível obter o Quadro 1:

Quadro 1: Análise dos projetos de Educação Ambiental da SEMMA-OP no PNMA.

\begin{tabular}{|c|c|c|c|c|c|c|}
\hline Etapas & Projeto 1 & Projeto 2 & Projeto 3 & Projeto 4 & Projeto 5 & $\begin{array}{l}\text { Total } \\
\text { Etapa }\end{array}$ \\
\hline $\begin{array}{l}\text { 1. Caracterização } \\
\text { socioeconómica }\end{array}$ & 1 & 0 & 0 & 1 & 0 & 2 \\
\hline $\begin{array}{l}\text { 2. Caracterizaçào } \\
\text { ambiental }\end{array}$ & 1 & 1 & 1 & 1 & 0 & 4 \\
\hline $\begin{array}{l}\text { 3. Percepção da } \\
\text { realidade ambiental }\end{array}$ & 1 & 1 & 1 & 1 & 1 & 5 \\
\hline 4. Reflexйо & 1 & 1 & 1 & 1 & 0 & 4 \\
\hline $\begin{array}{l}\text { 5. Proposta de } \\
\text { melhoria ambiental }\end{array}$ & 1 & 1 & 1 & 1 & 1 & 5 \\
\hline 6. Observaçăo & 1 & 1 & 1 & 1 & 1 & 5 \\
\hline 7. Registro & 0 & 0 & 1 & 1 & 0 & 2 \\
\hline 8. Exploraçăo & 0 & 1 & 1 & 1 & 0 & 3 \\
\hline 9. Apropriaçà̀ & 0 & 1 & 1 & 1 & 1 & 4 \\
\hline 10. Continuidade & 0 & 1 & 0 & 0 & 1 & 2 \\
\hline Total Projeto & 6 & 8 & 8 & 9 & 5 & - \\
\hline
\end{tabular}

Fonte: Dados da pesquisa (2015); modificado de Matheus (2005) e Horta et al. (1999).

Em decorrência do quadro elaborado foi possível constatar que $60 \%$ dos projetos avaliados não consideram características sociais das comunidades envolvidas. Nesta fase de avaliação ressalta-se o mérito dos projetos "Flores nas Pedras Camarinhas" e "A Escola Vai ao Parque". Lembrando que conforme mencionado por Matheus et al. (2005) a comunidade necessita de ações que desenvolvam o senso comunitário para se sentirem parte de um todo e conscientes do seu poder de mudança, engajando-se na melhoria da qualidade de vida. Nogueira (2002), em contraposição ao subjetivismo, elenca os estudos de Boudieu que critica as abordagens estruturalistas. Para ele há um habitus familiar ou de classe que conduz o sujeito ao longo do tempo e nos variados ambientes de ação. A estrutura social se perpetuaria porque os próprios indivíduos tenderiam a atualizá-la ao agir de acordo com o conjunto de disposição típico da posição estrutural na qual eles foram socializados.

O ator da "Sociologia da educação de Boudieu" não é nem um indivíduo isolado, consciente, reflexivo, nem o sujeito determinado, mecanicamente submetido às condições subjetivas em que ele age. Logo, torna-se relevante conhecer o habitus das comunidades que participaram destes projetos com vistas a adequar as atividades aos seus costumes, tornando-as mais próximas, acessíveis e de fácil assimilação a estes.

hevbea, sao raulo, v. 14, No 3: uy-30, '2019. 
Considerando que $60 \%$ os projetos existentes são voltados exclusivamente para educadores e educandos da rede pública de ensino, este dado corrobora a afirmativa anterior e permite inferir sobre a carência de boas iniciativas para as comunidades. Cabe ressaltar que, conforme Alves (2012), não só a escola, mas a tríade família-Igreja-escola, que se manteve como o alicerce de introdução das novas gerações aos padrões culturais dos últimos séculos, desestabiliza-se com a força das novas tecnologias.

O estudo como fruto da concentração, a descoberta como resultado do aprofundamento, essas noções que ganharam força na educação escolarizada, onde ficarão nesse frenesi de sons e imagens que se precipitam no nosso cotidiano? Há quase duas décadas, Novaes (1992, p. 13) escreveu que começávamos a nos esquecer de como é "fecundar o silêncio, entendendo silêncio não como ausência de palavra, mas, como condição de existência da própria palavra, pois é o intervalo entre as palavras - o silêncio - que dá sentido à linguagem". Logo, "Educar requer definir escolhas para o futuro" (ALVES, 2012).

A caracterização ambiental possui caráter de destaque em quase todos os projetos. Apenas o projeto "Uma vida, uma árvore", não se ocupa diretamente em disseminar entre os seus participantes as informações acerca do contexto ambiental em que estes estão expostos. Tal característica do projeto vai contra o proposto por Crespo (1998 apud SORRENTINO, 1997) quando este afirma que o principal papel da EA na sociedade é o de propiciar a sustentabilidade, tornando mais ecológicas as práticas sociais, incluindo a socialização dos indivíduos e a construção dos cidadãos.

A percepção da realidade ambiental é alvo de todos os projetos analisados. Esse fator é crucial, pois, os participantes muitas vezes encaram as informações acerca de temáticas ambientais com certo distanciamento pessoal, como temas prontos, verdades únicas restritas aos livros, imunes de qualquer tipo de contestação. Freire (1984) observa que "o processo de libertação não pode ser feito de forma impositiva sobre os oprimidos" a liberdade precisa ser uma escolha resultante de um processo de descoberta e não pode ser imposta por meio de informações 'mastigadas'.

Com base na premissa de percepção ambiental encontra-se enraizado os debates de percepção cultural. O debate contemporâneo sobre a diversidade e a diferença nas políticas e pesquisas em educação proposto por Rodrigues e Abramowicz (2013) traz a análise da maneira pela qual os conceitos de diferença e diversidade têm sido utilizados no debate contemporâneo brasileiro em educação e nas políticas públicas da área. Para os autores, duas hipóteses podem ser consideradas: a primeira é a de que cultura é um dispositivo que atua na diagramação simbólica do social, não só no sentido de procurar representar os grupos sociais ou de refleti-los, mas também demonstrando um caráter produtivo, de produzir a realidade e instituí-la; a segunda hipótese é a de que a não diferenciação entre diversidade e diferença esvazia ora a desigualdade, ora a diferença.

revista brasileira educação ambiental 
A diversidade colocada na esfera da cultura esvazia a desigualdade, pois, o que é chamado de social, que é o lugar da cultura (a cultura é uma linha do social), não se confunde e não é o setor econômico. O termo cultura, no sentido figurado, começa a impor-se no século XVIII. Progressivamente, cultura acaba por ser empregada para designar formação, educação do espírito. A diversidade foi entendida como uma forma de governo exercido pela política pública no campo da cultura, como uma estratégia de apaziguamento das desigualdades e de esvaziamento do campo da diferença, tendo como função borrar as identidades e quebrar as hegemonias. O lluminismo, que concebem a cultura como um caráter distintivo da espécie humana. Para eles, a cultura, é a soma dos saberes, considerada como totalidade, ao longo de sua história (CUCHE, 1999).

Seguindo essa linha de raciocínio, Nogueira (2002) coloca que a educação perderia o papel que lhe fora atribuído de instância salvadora e passaria a ser vista como uma das principais instituições por meio da qual se mantêm e se legitimam os privilégios sociais. Pois, a educação escolar, no caso de crianças oriundas de meios culturalmente favorecidos, seria uma espécie de continuação da educação familiar, enquanto para as outras crianças significaria algo estranho ou mesmo ameaçador. $\mathrm{O}$ que nos remete à próxima fase, a de reflexão.

A fase de reflexão é tida como essencial para assimilação do contexto observado, estando presente em $80 \%$ projetos analisados, sendo ausente apenas no "Projeto uma vida, uma árvore". O objetivo dessa etapa é que o participante entenda a conexão que existe entre a ação e a reação. Como exemplo o ato de refletir a relação de impacto que a produção de uma simples folha de papel acarreta nos recursos abiótico-bióticos visando o despontar de uma maior consciência ambiental na utilização desta, bem como a elaboração de possíveis alternativas para reduzir ou sanar tais problemas. Conforme Cunha (2016), o fator crucial é assumir a diferença entre informação e conhecimento, sendo a informação o resultado da exposição sistematizada de experiências humanas e determinados fenômenos. E o conhecimento, mais complexo, assume subjetividade como um valor. Ressalta-se que espaços educativos envolvem seres humanos em convivência, não há como desconsiderar os processos formativos que dela derivam e as formas de ver o mundo.

Quanto à fase "proposta de melhoria ambiental", todos os projetos atendem ao proposto por esta. Seja na recuperação de áreas degradadas, na preservação de recursos naturais ou mesmo na disseminação de consciência ambiental. A fase da observação, também presente em todos os projetos, mostra-se de grande utilidade para 0 aprendizado, pois possibilita que 0 participante entre em contato direto com o objeto estudado viabilizando o desenvolvimento de um olhar indagador sobre este bem. A aproximação entre o participante e a realidade estudada desenvolve vínculo entre estes. A observação é afim à percepção, tema recorrente em estudos ambientais como: de estudantes de curso superior de Turismo em de trabalho de campo no PNMA (FONSECA FILHO, 2014).

Revbea, São Paulo, V. 14, № 3: 09-30, 2019. 
A fase de registro esteve presente apenas nos projetos "A escola vai ao Parque" e "Curso de Educação Ambiental". Halbwachs (2006) corrobora que a melhor forma de "salvar" as lembranças de um grupo é fixá-las por escrito em uma narrativa, uma vez que as palavras e o pensamento possuem menor durabilidade do que foi escrito. Logo, a fim de obter resultados em longo prazo, faz-se interessante aplicar atividades vinculadas a esta etapa aos demais projetos.

A fase de exploração, presente em $60 \%$ projetos analisados, auxilia na compreensão de que o conhecimento não é um conteúdo morto, estático, sendo passível de alteração e de novas percepções. Nesse contexto, Matheus et al. (2005) colocam que as pessoas carecem de algo que desperte um senso comunitário, pois, ao sentirem-se parte de algo maior, estas tornam-se mais conscientes e engajam-se melhor em projetos de melhoria de qualidade de vida. Uma das formas mais eficientes de assegurar a compreensão das temáticas estudadas é por intermédio de oficinas de produção. Daí a importância da fase de apropriação. Esta etapa possibilita um maior aprofundamento do tema uma vez que estimula a busca por aplicabilidade destes, nela há uma maior interação com o tema e uma reflexão sobre a sua aplicação prática. Em quatro dos cinco projetos estudados, os participantes são instigados a encontrar vínculo entre a teoria e o contexto pessoal e a produzir algo que reflita este vínculo.

O quesito continuidade foi incluído na análise, pois, devido ao seu caráter de iniciativa pública, muitas vezes os projetos são abandonados pelos seus gestores. Conforme observado no quadro de análise, quase todos os projetos sofreram influência do processo de troca de gestão. Gastal e Moesch (2007, p.51) corroboram que a troca periódica de gestores a que o serviço público está sujeito, acarreta muitas vezes na quebra de continuidade de projetos e ações. Outra questão decorrente da constante troca de gestão é que não há mecanismos instituídos de avaliação da efetividade das ações dos projetos, nem previsões para o desenvolvimento destes. Uma das possíveis causas de tal quadro é a inexistência de mecanismos legais que disponham sobre prérequisito para contratação de pessoas para ocupar tais cargos, no que tange a formação profissional e acadêmica. Os cargos mais altos da gestão pública são provenientes de indicação política e, muitas vezes, a formação destes contratados é insuficiente e não condizem com o mínimo necessário para a função.

Embora esteja previsto em lei, a realização de estudos ambientais, por vezes, tais estudos são realizados superficialmente visando apenas um atendimento aos critérios legais. Como resultado, observa-se a existência de carências nos estudos vigentes que subsidiem o desenvolvimento de programas educativos, tanto naturais quanto culturais, de linguagem acessível à população na área do PNMA. O que ratifica estudo de Rodrigues et al. (2018) que identificaram que ações educativas conservacionistas em parques estaduais de São Paulo não alcançam ações práticas.

Estudos realizados por Machado e Alves (2014) apontam para o fato de que a comunidade, embora ciente das problemáticas ambientais existentes na 
área, em sua maioria, não se julga responsável pelos danos ao meio ambiente, pois não estão engajados no processo e, a seu ver, já arcam com custos altos para que seus governantes tomem a iniciativa para eles. Fato que aponta para a existência de falhas na etapa de apropriação.

Tais apontamentos apresentados no diagnóstico dos programas de EA são importantes para a compreensão dos postos fortes e fracos que cada iniciativa possui e para a indicação de áreas carentes de maiores esforços. Como esperado, a continuidade dos programas e o planejamento de atividades com retorno em um período maior de tempo mostrou-se falho. Na expectativa de oferecer sugestões estratégicas para tentar alterar esse quadro - embora não se analisou os princípios na relação teoria e prática dos programas, buscou-se a ampliação do escopo do estudo para um planejamento estratégico.

\section{Rio das Velhas Azul}

Com base no exposto a respeito dos programas de Educação Ambiental do PNMA, aplicando a metodologia "curva de valor" (matriz: Eliminar, Elevar, Reduzir e Criar) de Kim e Mauborgne (2005, p. 35), foi possível estabelecer um quadro sistemático analítico (Quadro 2).

A Matriz de avaliação de valor é um instrumento analítico utilizado tanto no diagnóstico de ações como no desenvolvimento estratégico. Permite compreender os atributos competitivos de cada projeto bem como as áreas que carecem de maiores esforços para a reorganização do foco. Ao induzir os gestores a responder às quatro perguntas, destaca os pontos competitivos, estimula o desenvolvimento de novas estratégias e agir de acordo com elas.

Uma boa estratégia, de acordo com a matriz, é aquela que possui baixo custo, foco, singularidade e uma mensagem consistente de marketing. Tais atributos seriam básicos para a eficácia estratégica das ações. Aplicando-as aos projetos de EA foi possível identificar as áreas dos projetos que estavam excedendo em gastos, como a manutenção de algumas estruturas fixas desnecessárias no Programa "Flores nas Pedras Camarinhas" e áreas que poderiam ser alvo de maior investimento como a divulgação e o marketing do programa "A Escola vai ao Parque".

No decorrer da análise e construção da matriz surgem novas ideias estratégicas que poderiam alavancar os programas de $E A$, como a informatização no programa "Plano Integrado de Ações de Prevenção e Combate a Incêndios Florestais" e a mudança de foco e investimento da marca no programa "Flores nas Pedras Camarinhas" para obtenção de uma mensagem mais consistente. O que pode vir a fomentar um programa contínuo pelo poder público municipal, a exemplo do prognóstico voltado à gestão de resíduos sólidos proposto por Saraiva et al. (2018) para o município de São Francisco/PB. Ou seja, da nascente em Ouro Preto à foz em São Francisco a condição do "rio que corre para o mar" vai limpando tanto suas águas quanto a consciência ambiental dos stakeholders, por meio de programas de Educação Ambiental. 
Quadro 2: Análise dos projetos de Educação Ambiental - Matriz estratégica "Oceanos Azuis".

\author{
REDUZIR \\ (Quais atributos devem ser reduzidos bem abaixo dos \\ padró es se toriais?) \\ Programa 1 : Projeto Flores nas Pedras Camarinhas \\ Investimento em estrutura fixa; \\ Falta de organização da equipe operacional; \\ Desmotivação da equipe (associados); \\ Programa 2: Plano Integrado de Prevenção e Combate à \\ Incêndios Florestais \\ Custos com formação de brigadistas sem compromisso com \\ a con tinuidade do projeto; \\ Carência de investimentos fin anceiros; \\ Desmotivação da equipe; \\ Custos com transporte através de planejamento tático \\ operacional das atividades.
}

\section{Programa 3: Curso de Educação Ambiental;}

Despesas com a tividades práticas;

Deficiências no dominio das temáticas abordadas;

Equipe de acompanhamento despreparada (estagiários);

Pouca dispon ibilização de recursos pela gestão municipal;

\section{Programa 4: A Escola vai ao Parque;}

Custos com divulgação impressa das atividades do programa;

Carências técnicas e pedagóg icas;

Deficiencias na realização de trabatho coletivo da equipe.

\section{Programa 5: Uma vida, uma árvore}

Custos para o plantio incentivando o apoio e participação da comunidade local;

Custos com manutenção das mudas optando por arreas que demandem menor acompan hamen to para o desenvolvimento das plantas;

Desinteresse pela elaboração de atividades de educação ambiental durante a efe tivação do plantio.

\section{ELE VAR}

(Quais atributos devem ser elevados bem acima dos padrões setoriais?)

Programa 1: Projeto Flores nas Pedras Camarinhas Programas de capacitação empresarial, saúde e processos ambientais na sede da associação;

Investimento em insumos para produção inicial;

Apoio para cálculo no valor de venda da produção;

Investir na motiva ção dos associados para a nova atividade;

\section{EL IMINAR}

(Quais atributos nunca oferecidos pelo setor devem ser criados?)

Programa 1: Projeto Flores nas Pedras Camarinhas Proje to de irrigação do galpão destinado ao viveiro das Camarinhas.

Despreparo técnico da equipe (associados);

Centralização de gestão no presidente da Associação.

\section{Programa 2: Plano Integrado de Prevençâo e Combate à Incêndios Florestais}

Despesa com telefonia fixa;

Desarticulação entre os setores en volvidos;
Programa 3: Curso de Educação Ambiental;

Despesas com alimentação e estadia de professores e palestrantes convidados de outras localidades;

Carência de investimento financeiro por empresas do setor privado.

\section{Programa 4: A Escola vai ao Parque;}

Falhas didaticas na ex ecução das fases do projeto;

Carência de investimento financeiro por empresas do setor privado;

\section{Programa 5: Uma vida, uma árvore;}

A falta de envolvimento da comunidade do entomo nas atividades do plantio das mudas;

Pouco incentivo à percepção ambiental que envolve o projeto.
Programa 2: Plano Integrado de Prevenção e Combate à Incềndios Florestais

Atividades educativas de prevenção;

Cursos de capacitação;

Participação em atividades volta das para a comunidade;

Apoio ao trabatho de grupos de lideranças informais nas

\section{CRIAR}

(Quais atributos nunca oferecidos pelo setor devem ser criados?)

Programa 1: Projeto Flores nas Pedras Camarinhas

Seria mais interessante, e com custos mais baixos, se cad associado desenvolvesse um espaço na própria residência para o cultivo das plantas ornamentais;

Promover mostras e feiras mensais no espaço fisico cedido pela PMOP para comercialização das plantas omamentais produzidas pelos associados.

Desenvolver uma marca para os produtos da Associação;

Promover divulgação em midias e meios de comunicação diversos;

Desenvolver algum produto complementar para ser incluido nas a tividades da associação;

Uniforme para distinguir associados nas feiras;

Elaboração e publicação de livro de histórias que relatam casos interessantes repassados por antepassados sobre as plantas comercializadas e reverter o bucro para à associação.

\section{Programa 2: Plano Integrado de Prevenção e Combate} Incêndios Florestais

Concurso para a escotha da mascote do grupo, utilizado nas campanhas de publicidade;

Criar taxa para a participação em cursos de ca pacitação;

Fonte: Dados da pesquisa (2018). revista brasileira 
A matriz cria condições para que os gestores possam ver o futuro dos programas no presente. Quando um projeto se confunde com os demais, significa que ele se perdeu no oceano vermelho das competições. Tal fato pode ser observado no programa "Uma Vida, Uma Árvore" cujas atividades propostas se confundem, por vezes, com as existentes no programa "A Escola vai ao Parque". É possível notar na matriz o excesso de atributos sem retorno, como no caso de investimentos em estadia no programa "Curso de Educação Ambiental".

A ferramenta de modelo analítico matriz estratégica "Oceanos Azuis" permite, portanto, a inserção de técnicas de planejamento que possibilitam aos gestores uma melhor visualização dos atributos existentes nos programas de EA com vistas à eliminação de atributos como gastos desnecessários e mensagens controversas, proporcionando a elaboração e o estabelecimento de novas ações estratégicas baseadas na singularidade, baixo-custo e coerência que auxiliam a conquista de setores mais atrativos e lucrativos, não explorados pelo mercado, os chamados Oceanos Azuis.

\section{Conclusões}

A Educação Ambiental é alvo de diversas ações do setor público junto à comunidade. Entretanto, a eficiência no planejamento de suas atividades e os resultados obtidos das suas ações vem apresentando-se de forma insatisfatória. Principalmente graças às características imediatistas deste setor. Tal premissa norteou a realização do presente trabalho a partir de cinco estudos de caso na relação políticas públicas ambientais e unidade de conservação em um município tradicionalmente voltado ao turismo cultural pelo seu patrimônio equivalente. Assim, na etapa do "Diagnóstico dos programas de EA" estabeleceu-se dez itens relevantes para identificar a eficiência e continuidade das ações de EA, dos quais três dos cinco programas analisados atenderam satisfatoriamente a maioria dos requisitos apresentados, o que aponta para uma boa efetividade de gestão da UC.

Tal diagnóstico favoreceu a apresentação de propostas para melhorias dos programas na "Etapa de Planejamento Estratégico" como a implementação de atividades, mecanismos de controle de qualidade e eficiência, maior engajamento da população residente e da iniciativa privada como forma de melhorar a relação de apropriação por parte da comunidade e de reduzir o impacto negativo das constantes mudanças ocorridas na administração do setor público que interfere na continuidade dos projetos como ficou comprovado no estudo.

A elaboração de quadro analítico dos projetos a luz das bibliografias selecionadas para o tema, em especial a curva de valor, proposta na estratégia "Oceanos Azuis", proporcionou uma visão reflexivo-crítica do panorama encontrado. Como resultado da análise, foi possível executar a última etapa que consistiu em tecer apontamentos para ampliação do público-alvo a ser contemplado e para melhorias nos programas de EA analisados.

Revbea, São Paulo, V. 14, № 3: 09-30, 2019. 


\section{Agradecimentos}

Às unidades de conservação ouro-pretanas pelas contribuições à pesquisa e à Secretaria Municipal de Meio Ambiente de Ouro Preto pelo apoio.

\section{Referências}

ALMEIDA J.A.; RIEDI, M.; FROEHLICH, J.M. (Org.). Turismo rural e desenvolvimento sustentável. Campinas-SP: Papirus, 2001.

ALVES, C. O educador e sua relação com o passado. Educação em Revista. Belo Horizonte, v. 28, n. 3, p. 205-217, set. 2012.

BRASIL. Constituição da República Federativa do Brasil. Brasília, DF: Senado Federal: Centro Gráfico, 1988. Disponível em: <http://www.planalto.gov.br/ccivil 03/constituicao/constituicao.htmhttp://www.pl analto.gov.br/ccivil 03/constituicao/constituicao.htm>. Acesso em: 3 jul. 2019.

BRASIL. Lei no 9.985. Brasília: Ministério do Meio Ambiente, 2000. Disponível em: <http://www.planalto.gov.br/ccivil 03/leis/L9985.htm>. Acesso em: 3 jul. 2019.

CARVALHO, A.F. et al. Zoneamento Ecológico-Econômico da Área de Proteção Ambiental Cachoeira das Andorinhas. Viçosa-MG: Universidade Federal de Viçosa, 2006.

CHAVES, V.C.A gestão social no projeto "Flores e Águas da Nascente do Velhas". Revista VITAS - Visões Transdisciplinares sobre Ambiente e Sociedade, ano V, n. 11, p. 1-16, 2015.

CUCHE, Denys. A Noção de Cultura nas Ciências Sociais. Bauru-SP: EDUSC, 1999.

CUNHA, M.I. Inovações na educação superior: impactos na prática pedagógica e nos saberes da docência. Revista em Aberto. v. 29, n. 97. p. 87-101, set/dez. 2016.

FONSECA FILHO, R.E. Turismo e educação para além dos muros e cercas de duas unidades de conservação de Ouro Preto (MG). Anais... III SIMPÓSIO DE ÁREAS NACIONAIS PROTEGIDAS, v. 1, p. 489-499, 2014.

FREIRE, P. Educação Popular. São Paulo: Todos os Irmãos Ltda., 1984.

GASTAL, S.; MOESCH, M. Turismo, políticas públicas e cidadania. São Paulo: Aleph, 2007.

GATTI, Bernadete A. Educação, escola e formação de professores: políticas e impasses. Educar em Revista. Curitiba, n. 50, p. 51-67, dez. 2013.

HALBWACHS, M. A. memória coletiva. São Paulo: Ed. Centauro, 2006 
HENRIQUES, R.; TRAJBER, R.; MELLO, S.; LIPAI, E.M.; CHAMUSCA, A. (Org.). Educação Ambiental: aprendizes da sustentabilidade. Brasília: Ministério da Educação, 2007.

HORTA, M.L.P.; GRUNBERG, E.; MONTEIRO, A. Q. Guia Básico de Educação Patrimonial. Brasília: IPHAN / Museu Imperial, 1999.

IBASE. Gestão participativa em unidades de conservação. Rio de Janeiro: Instituto Brasileiro de Análises Sociais e Econômicas, 2006.

ICMBIO. Manual para formação de brigadista de prevenção e combate aos incêndios florestais. Brasília: Instituto Chico Mendes de Conservação da Biodiversidade, 2010.

JACOBI, P. Educação Ambiental, cidadania e sustentabilidade. Cadernos de Pesquisa, n. 118, p. 189-205, 2003.

KIM, W.C.; MAUBORGNE, R. A estratégia do oceano azul: como criar novos mercados e tornar a concorrência irrelevante. Rio de Janeiro: Elsevier, 2005.

KRIPPENDORF, Jost. Sociologia do Turismo: para uma nova compreensão do lazer e das viagens. São Paulo: Aleph, 2006.

LAYRARGUES, P.P. Educação para a gestão ambiental: a cidadania no enfrentamento político dos conflitos socioambientais. 2002. In: LOUREIRO, C.F. B.; LAYRARGUES, P.P.; CASTRO, R. S. (Org.). Sociedade e meio ambiente: a Educação Ambiental em debate. São Paulo: Cortez, 2002. p. 87-155.

LIMA, G.S.; RIBEIRO, G.A.; GONÇALVES, W. Avaliação da efetividade de manejo das unidades de conservação de proteção de integral em Minas Gerais. Revista Árvore, v. 29, n. 4, p. 647-653, 2005.

LOUREIRO, C.F.B.; CUNHA, C.C. Educação Ambiental e gestão participativa de unidades de conservação: elementos para se pensar a sustentabilidade democrática. Ambiente \& Sociedade, Campinas v. XI, n. 2, p. 237-253, 2008.

MACHADO, S.F. Caracterização dos visitantes e percepção de impacto ambiental em duas unidades de conservação de Ouro Preto - MG. Ouro Preto, Monografia (Bacharelado em Turismo), Universidade Federal de Ouro Preto, 2013.

MACHADO, S.F.; ALVES, K.S. Turismo e meio ambiente: relação de interdependência. Revista Meio Ambiente e Sustentabilidade, v. 6, n. 3, p. 219-241, 2014.

MATHEUS, C.E.; MORAES, A.J.; CAFFAGNI, C.W.A. Educação Ambiental para o turismo sustentável. São Carlos-SP: Rima, 2005.

MMA. Gestão participativa do SNUC. Brasília: Ministério do Meio Ambiente, 2004. 
MORRO DA QUEIMADA. Parque Arqueológico do Morro da Queimada. Disponível em: <http://morrodaqueimada.fiocruz.br/parque-arqueologicoapresentacao.php>. Acesso em: 3 jul. 2019.

MURTA, I.B.D. Representações sociais do ambiente preservado: estudo de caso no município de Ouro Preto/MG. Belo Horizonte, Dissertação (Mestrado em Geografia), Universidade Federal de Minas Gerais, 2012.

NOVAES, Adauto (Org.). Tempo e história. São Paulo: Companhia das Letras/ Secretaria Municipal de Cultura, 1992.

NOGUEIRA, M.A.A sociologia da educação de Pierre Bourdieu: limites e contribuições. Educação e Sociedade, v. 23, n. 78, p. 15-35, 2002.

O INCONFIDENTE. IV Fórum de Educação Ambiental de Ouro Preto. 2010. Disponível em: <http://www.oinconfidente.com.br/noticias/acervo/163>. Acesso em: 3 jul. 2019.

O INCONFIDENTE. Políticas ambientais de Ouro Preto recebem prêmios estaduais e nacionais. Disponível em: <http://www.oinconfidente.com.br/ noticias/acervo/895>. Acesso em: 3 jul. 2019.

O INCONFIDENTE. Prefeitura de Ouro Preto lança projeto "A Escola vai ao Parque". Disponível em: <http://www.oinconfidente.com.br/noticias/ acervo/428>. Acesso em: 3 jul. 2019.

O LIBERAL. Alunos de escolas municipais visitam Parque das Andorinhas. Disponível em: $\quad<$ http://www.jornaloliberal.net/noticia/alunos-de-escolasmunicipais-visitam-parque-das-andorinhas/>. Acesso em: 3 jul. 2019.

O LIBERAL. Combate a incêndios ganha reforço em Ouro Preto. Disponível em: <http://www.jornaloliberal.net/noticia/combate-a-incendios-ganha-reforcoem-ouro-preto/>. Acesso em: 3 jul. 2019.

OURO PRETO. Lei Municipal $\mathbf{n}^{\circ}$. 305. Cria o Parque Municipal Cachoeira das Andorinhas. Ouro Preto-MG: Câmara Municipal de Ouro Preto, 1968.

OURO PRETO. Lei Municipal n. 69. Ouro Preto-MG: Câmara Municipal de Ouro Preto, 2005.

PMOP. Secretaria de Meio Ambiente realiza mais uma etapa do projeto Uma Vida, Uma Árvore. Disponível em: <http://www.ouropreto.mg.gov.br/ noticia/471/secretaria-de-meio-ambiente-realiza-mais-uma-etapa-do-projetouma-vida-uma-arvore >. Acesso em: 3 jul. 2019.

PMOP. Programas da Secretaria Municipal de Meio Ambiente de Ouro Preto. 2016a. Disponível em: <http://www.ouropreto.mg.gov.br/ veja/39/21/programas>. Acesso em: 3 jul. 2019.

PORTAL MARIANA. Ouro Preto recebe projeto "Uma Vida, Uma Árvore". Disponível em: <http://www.portalmariana.org/cidades/ouro-preto-mg/ouropreto-recebe-projeto-uma-vida-uma-arvore/\#.WA4CQfRA 2Y>. Acesso em: 3 jul. 2019. 
RET, PNMA. Relatório de Estudos Técnicos do Parque Natural Municipal das Andorinhas. Ouro Preto-MG: SEMMA/OP, 2010.

REZENDE, J.L.P.; ALVES, R.G.; BORGES, L.A.C.; FONTES, M.A.L.; ALVES, L.W.R Avaliação da gestão das UC do Sistema Estadual de Áreas Protegidas de Minas Gerais. Geografias, v. 6, n. 1, p. 87-106, 2010.

REZENDE, R.A. A fragmentação da flora nativa como instrumento de análise da sustentabilidade ecológica de áreas protegidas - Espinhaço Sul (MG). Ouro Preto, MG, Tese (Doutorado em Ciências Naturais), Universidade Federal de Ouro Preto, 2011.

RODRIGUES, L.M.; CAMPANHÃO, L.M.B.; BERNARDI, Y.R. Tendências político-pedagógicas de Educação Ambiental em unidades de conservação: o caso dos Parques Estaduais de São Paulo. Revbea, v. 13, n. 1, p 192-212, 2018.

RODRIGUES, T.C.; ABRAMOWICZ, A. O debate contemporâneo sobre a diversidade e a diferença nas políticas e pesquisas em educação. Educação e Pesquisa, v. 39, n. 1, p. 15-30, 2013.

RUSCHMANN, D.V. Turismo e planejamento sustentável: A proteção do meio ambiente. Campinas-SP: Papirus, 1997.

SANTOS, B. de S. A universidade no Século XXI. São Paulo: Cortez, 2010.

SARAIVA, A.G.; SOARES, L.V.; SILVA, R.M. da. Implantação de programas e ações de Educação Ambiental no município de São Francisco (PB). Revbea, v. 13, n. 3, p. 109-121, 2018.

SCHELEDER, G.A. Educação Ambiental em unidades de conservação. Curitiba, Trabalho de Conclusão de Curso (Ciências Biológicas), Universidade Positivo, 2008.

SIQUEIRA, A.E. et al. Guia de campo do Parque Nacional da Tijuca. Rio de Janeiro: UERJ / IBRAG, 2013.

S.O.S. AVENTURAS. Brigada 1 - Combate Voluntário a Incêndios Florestais. Disponível em: <http://www.sosaventura.com/2013/09/brigada-1-combatevoluntario-incendios. html>. Acesso em: 3 jul. 2019.

URRY, John. O olhar do turista. São Paulo: Editora Studio Nobel/SESC, 2001. WWF/ICMBIO. Efetividade de gestão das unidades de conservação federais do Brasil: resultados de 2010. Brasília: WWF / ICMBIO, 2012. 